\title{
Development of sprayed backfill technology
}

\author{
J. Pacovský \& J. Št’ástka \\ Centre of Experimental Geotechnics, \\ Czech Technical University in Prague, Czech Republic
}

\begin{abstract}
It is envisaged that sprayed backfill technology will be used to fill the access galleries of deep geological repositories for radioactive waste produced by nuclear power plants. This technology has already been experimentally tested at several locations outside the Czech Republic. The basic sprayed material consists of bentonite, a natural ecological material which fulfils all the quality demands required in the construction of deep geological repository engineered barriers including, in particular, swelling capacity, impermeability, high plasticity and self-healing ability. It is anticipated that spraying will serve for backfilling those underground spaces inaccessible to ordinary machinery. The space filled by sprayed backfill must prevent the penetration of hazardous radionuclides to the same extent as those spaces backfilled with hand- and mechanically-compacted natural bentonite or its mixture with crushed rock.
\end{abstract}

Keywords: radioactive waste, engineered barrier, sprayed backfill, shotclay, bentonite.

\section{Introduction}

Sprayed backfill technology, also known as shotclay technology, is based on the already commonly employed technology of sprayed concrete (shotcrete). Of the two existing technological procedures used in shotcreting ("dry" and "wet" methods), the dry process was selected for the delivery of sprayed backfill.

During the dry process, the sprayed mixture is transported pneumatically, via transport hoses, from the spraying machine to the spray site in the dry state. The ends of the transport hoses are fixed with spraying nozzles into water is channelled. Thus the sprayed mixture is hydrated to the desirable moisture content level within the nozzle. 
Sprayed backfill technology will serve for filling difficult to access spaces which cannot be backfilled in other ways. The remaining spaces will be backfilled with bentonite or its mixture with crushed rock. Backfill is compacted layer upon layer.

The dry density of the sprayed material must be at least the same as the dry density of the backfill achieved by mechanical compaction, Fig. 1.

The development of such technology at the Centre of Experimental Geotechnics (CEG) uses Czech bentonite and the Czech SSB 24 spraying machine (manufactured by Filamos Ltd.).

\section{BACKFILLING}

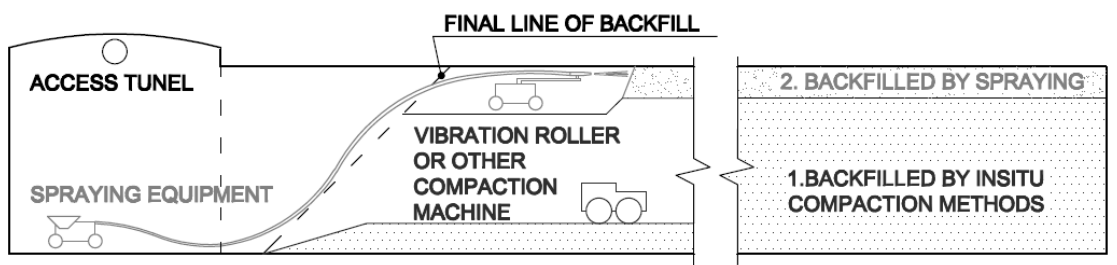

Figure 1: $\quad$ Access gallery backfilling by compacting and spraying.

\section{A short outline of foreign experience}

Shotclay technology has undergone thorough testing at several foreign locations to date e.g. at AECL Canada (Atomic Energy of Canada Limited), SKB (Swedish Nuclear Fuel and Waste Management Co.) in Sweden and the Radioactive Waste Management Funding and Research Centre, Tokyo, Japan.

Certain institutions have attempted to develop technology suitable for use in the application of sprayed buffers (Japan), others for sprayed backfill (Canada, Sweden). The buffer is that part of the engineered (geotechnical) barrier situated closest to the canister containing radioactive waste. The buffer must comply with higher quality demands than the backfill. The sprayed buffer must possess a minimum dry density of $1600 \mathrm{~kg} / \mathrm{m}^{3}$ since it is responsible for sealing the nearest surroundings of the canister. Those spaces more distant from the canister, such as access galleries, which must be backfilled after repository closure, do not have to meet such strict demands; a backfill dry density value here of $1400 \mathrm{~kg} / \mathrm{m}^{3}$ is sufficient.

Dry density is an important parameter as it affects practically all the relevant geotechnical material parameters: swelling capacity, impermeability, plasticity and self-healing ability.

Various types of bentonite have been tested in Canada and Sweden, including bentonite mixtures with sand and bentonite pellets and bentonites of different grain size and moisture content. Both of the relevant institutions have managed to define both the material and the working procedure that best ensure the required dry density of sprayed backfill (Dixon [1]). 
The development of sprayed buffer technology in Japan was set much higher demands. In order to achieve the required dry density $\left(1600 \mathrm{~kg} / \mathrm{m}^{3}\right)$ the sprayed material used contained bentonite cooled to $-10^{\circ} \mathrm{C}$ employing ice slush instead of water. Part of the development process involved the design and construction of a supersonic spraying nozzle which further enhanced the kinetic energy of the sprayed material thus maximising the compaction effects (Kobayashi et al. [2]).

\section{Development of sprayed backfill technology at the Centre of Experimental Geotechnics}

It is estimated that the construction of a deep geological repository will require approximately 500 thousand tonnes of natural bentonite.

The greater part of the bentonite will serve for backfilling the access galleries (adits) and the rest will be used for the construction of a sealing layer which will be in direct contact with the canisters (buffer).

After deep repository closure, the backfilled access galleries will form part of a multibarrier system which will prevent the penetration of radionuclides into the biosphere for a period of up to hundreds of thousands of years.

The objective of the research being carried out at the Centre of Experimental Geotechnics (CEG), Czech Technical University in Prague, is to develop sprayed backfill technology using Czech bentonite which will also include the design of the spraying machine.

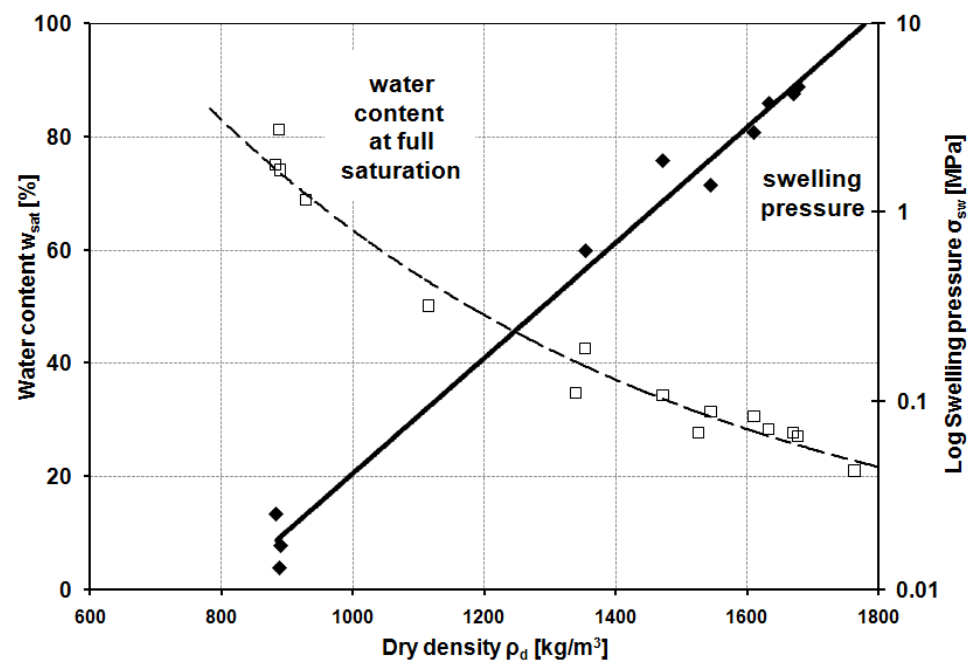

Figure 2: Swelling pressure / dry density relationship.

\subsection{Sprayed material}

Countries engaged in research into engineered barriers based on bentonite either try to use their own, high-quality domestic resources, or seek more cost-effective resources abroad whilst maintaining the same level of quality. 


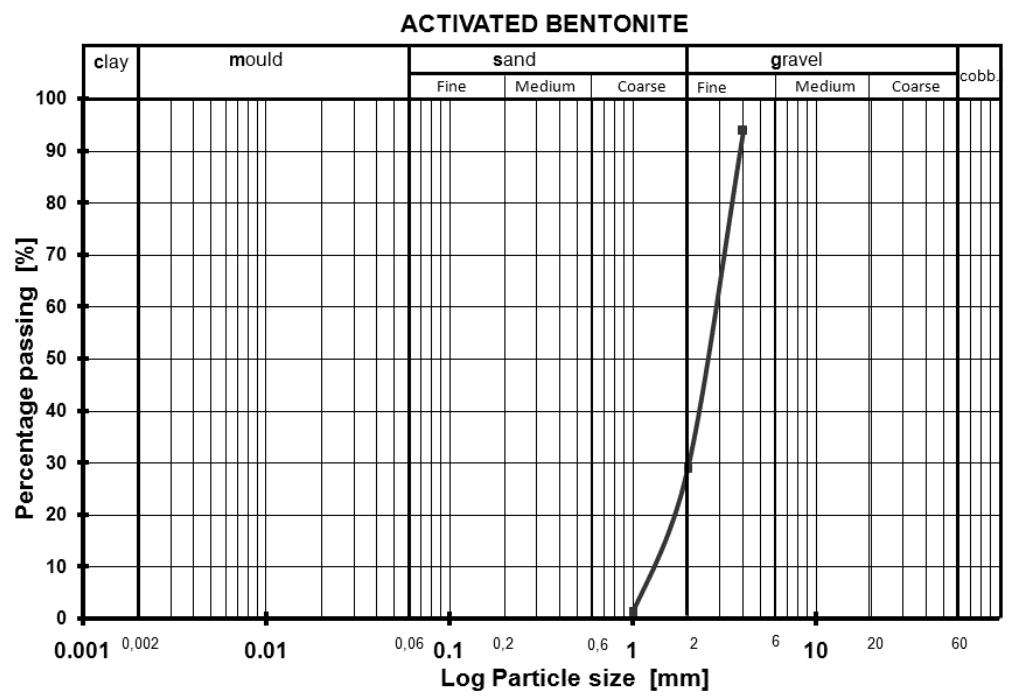

MIXTURE 1:1

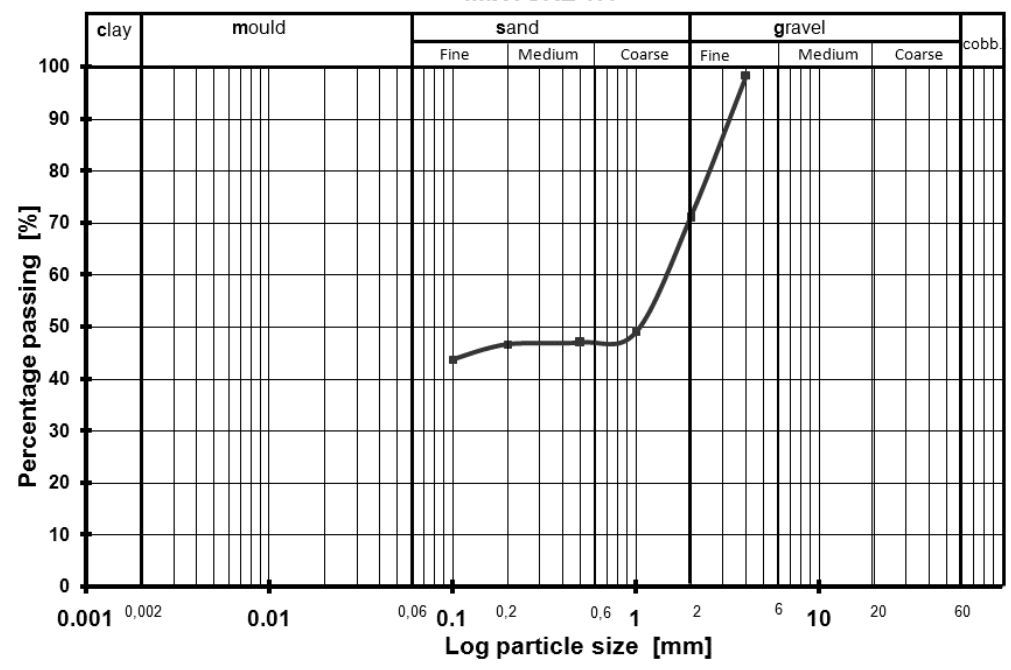

Figure 3: Grain size curves of tested sprayed materials.

The Czech Republic possesses extensive deposits of bentonite which is used in various domestic industries (foundries, construction, food industry etc.).

The CEG uses bentonite from the Rokle deposit as the basic material in the development of sprayed backfill technology. Bentonite is basically residual claytype rock with massive sorption, swelling and plasticity abilities reflected in minerals which make up the clay, particularly montmorillonite.

Bentonite from the Rokle locality is calcium magnesium bentonite with a montmorillonite content of $65-80 \%$. It possesses excellent swelling and self- 
healing abilities, high plasticity and minimum permeability. Its plasticity index Ip is around $70 \%$. Highly compacted to a dry density of $1750 \mathrm{~kg} / \mathrm{m}^{3}$ it is able to develop swelling pressures of up to $6 \mathrm{MPa}$ with a permeability coefficient in such a highly compacted state of $\mathrm{k}=10^{-13} \mathrm{~m} / \mathrm{s}$, Fig. 2 .

Research into sprayed backfill to date has used different size fractions of Rokle bentonite (see below), Fig. 3.

The design of the sprayed mixture involved the participation of Keramost Ltd., a manufacturer of industrial bentonites (KERAMOST [3]).

\subsection{Design of plant technology}

Shotclay technology (sprayed buffer and/or sprayed backfill) development uses the same spraying device (machine) as that used for shotcreting technology in underground structures.

The application of shotcrete is based on two procedures - dry or wet.

In the dry process, the sprayed material is pneumatically transported by means of hoses to the spraying nozzle where it is hydrated at the moment it leaves the nozzle. The main advantages of this procedure lie in there being a higher sprayed matter compaction level, easier transport of the dry mix over long distances and no requirement to clean the hoses should there be an interruption to the transport cycle; the main disadvantage lies in high dust emissions.

The wet process involves the transport of wet (moistened) sprayed mixture from the machine via hoses all the way to the spraying nozzle. The main advantage here is minimum dust emissions. The main disadvantages however include the lower sprayed matter compaction level and, in particular, the hydration of the required volume of the bentonite mixture in the spraying machine.

Consequently, research into sprayed backfill carried out abroad to date has, almost exclusively, involved dry spraying technology; for similar reasons, this technology was also selected for further development by CEG.

The decision-making process concerning the choice of spraying machine to be used in the study of spray technology involved an evaluation of the parameters of a total of eight machines produced both by domestic and foreign

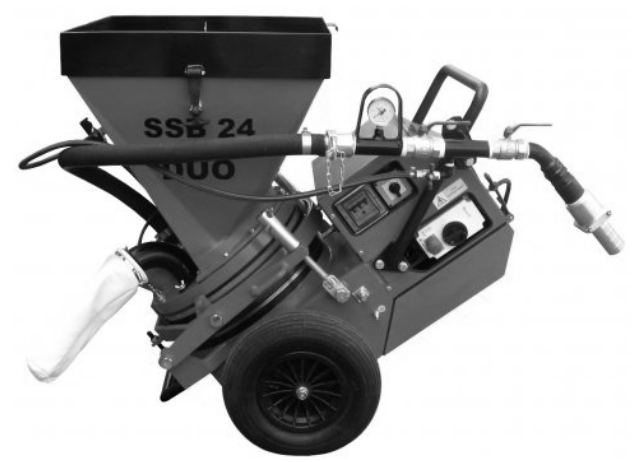

Figure 4: $\quad$ SSB 24 machine. 
manufacturers: Airplaco, Aliva, Allentown, Blastcrete, Delta Ltd., Filamos, Reed and Rockcreter. The final choice was the Czech manufacturer FILAMOS [4] which agreed to either develop a new machine or modify its existing models for CEG use. Following extensive consultation with the manufacturer, the SSB 24 machine was chosen, Figure 4.

The SSB 24 machine serves for spraying concrete mixtures using the dry process. The output of the machine is up to $6 \mathrm{~m}^{3}$ of mixture per hour, the consumption of air at a transport distance of approximately $40 \mathrm{~m}$ is $6-8 \mathrm{~m}^{3} / \mathrm{min}$; air pressure is $0.5-0.6 \mathrm{MPa}$. The maximum grain size of the transported material is $16 \mathrm{~mm}$, the horizontal transport distance a maximum of $300 \mathrm{~m}$, and the vertical distance up to $100 \mathrm{~m}$.

\subsection{Requirements for sprayed backfill}

Bentonite, which, it is assumed, will form the basic material for the construction of deep geological disposal geotechnical barriers, must fulfil the following requirements:

a) high swelling ability

b) minimal permeability

c) high plasticity

d) self-healing ability

The swelling ability of bentonite is a well-known characteristic and is the consequence of its mineralogical composition (mainly the content of montmorillonite). Swelling ability is verified by measurement of the swelling pressure which increases with increased dry density (compaction). The swelling pressure of natural, loose Rokle bentonite is in the region of $300 \mathrm{kPa}$. If, however, this bentonite is highly compacted to a dry density of $1750 \mathrm{~kg} / \mathrm{m}^{3}$, its swelling pressure (swelling ability) increases to $6 \mathrm{MPa}$ (i.e. 20 times). Swelling pressure ensures that all cracks, joints and discontinuities are filled and sealed to the maximum extent.

The permeability of bentonite also depends on dry density; the higher the dry density, the lower the permeability. The permeability (filtration) coefficient of Rokle bentonite, highly compacted to a dry density of $1750 \mathrm{~kg} / \mathrm{m}^{3}$ is equal to $\mathrm{k}=10^{-12}-10^{-13} \mathrm{~m} / \mathrm{s}$. The impermeability of bentonite eliminates (or at least minimises) the migration of hazardous radionuclides through the liquid medium.

The plasticity of bentonite is a characteristic described by means of consistency limits - the shrinkage limit $\left(\mathrm{w}_{\mathrm{S}}\right)$, plasticity limit $\left(\mathrm{w}_{\mathrm{P}}\right)$ and liquid limit $\left(\mathrm{w}_{\mathrm{L}}\right)$. All three limits are defined by the moisture content at which specified limit material behaviour is reached. The difference between the liquid limit $\mathrm{w}_{\mathrm{L}}$ and the plasticity limit $\mathrm{w}_{P}$ expresses the so-called plasticity index $\mathrm{I}_{\mathrm{p}}=\mathrm{w}_{\mathrm{L}}-\mathrm{w}_{\mathrm{P}}$. The material assumes plastic behaviour in the moisture content range between the $\mathrm{w}_{\mathrm{L}}$ and $\mathrm{w}_{\mathrm{P}}$ limits. Therefore, the greater the $\mathrm{I}_{\mathrm{p}}$ index, the more plastic the material is. A material with a high plasticity index more easily fills discontinuities, even with substantial changes in moisture content (in the range of $\mathrm{I}_{\mathrm{p}}$ ). The Rokle material exhibits $\mathrm{I}_{\mathrm{p}}=70 \%$.

Self-healing ability is primarily due to the swelling ability and high plasticity of bentonite (Pacovský [5]). 
The bentonite used for sprayed backfill must necessarily meet the requirement that the dry density of the sprayed material is not lower than the dry density of mechanically compacted backfill. In order to roughly specify maximum potential mechanical compaction, the Proctor Standard test is used, which specifies the optimum moisture content at which the required maximum dry density is achieved.

Given the fact that sprayed backfill technology will be applied in underground spaces fitted with artificial ventilation, the development of technology involving minimum dust emissions is essential.

A further important technological parameter is the required output of the spraying machine which depends on the size of the spaces to be backfilled; the presumed minimum output must be at least $5 \mathrm{~m}^{3} /$ hour.

\subsection{Test spraying}

In the first development phase, the SSB 24 was tested both for spraying concrete and for spraying clays including bentonite mixtures. A component part of this phase involved the specification of parameters concerning dust emissions during spraying operations. Test spraying was performed on a spray test wall. Two basic size fractions of Rokle bentonite were tested with different amounts of water (the so-called w/c ratio) during individual spraying applications. The result of the first spraying application was unsuccessful due to unacceptably high dust emissions, Figure 5.

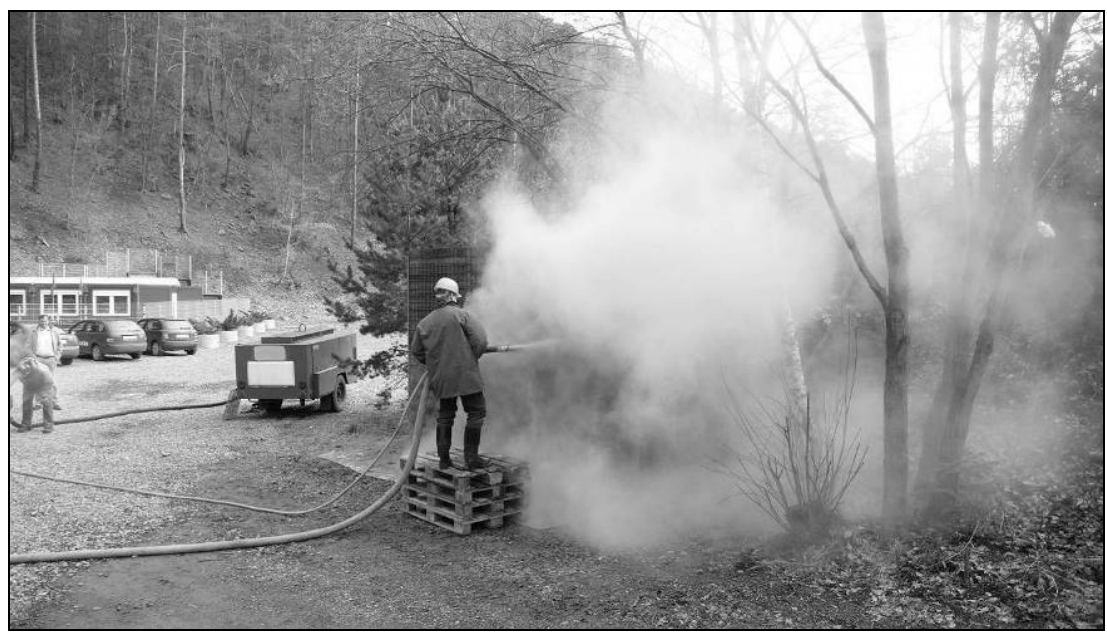

Figure 5: Dust emissions during $1^{\text {st }}$ test spraying application.

Changes in the material grain size curve and the w/c ratio produced both favourable (minimum) dust emissions and the desired spraying density at the third attempt, Figure 6.

A simple flow indicator was designed to allow the exact dosage of water (w/c ratio), Figure 7. 


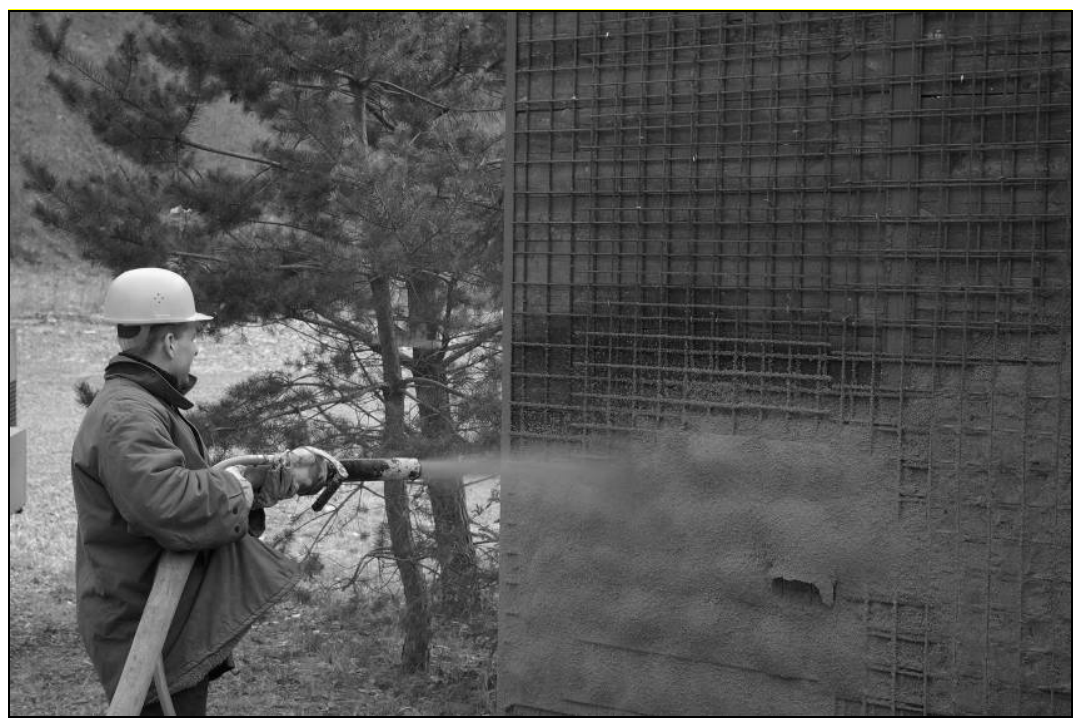

Figure 6: Dust emissions during $3^{\text {rd }}$ test spraying application.

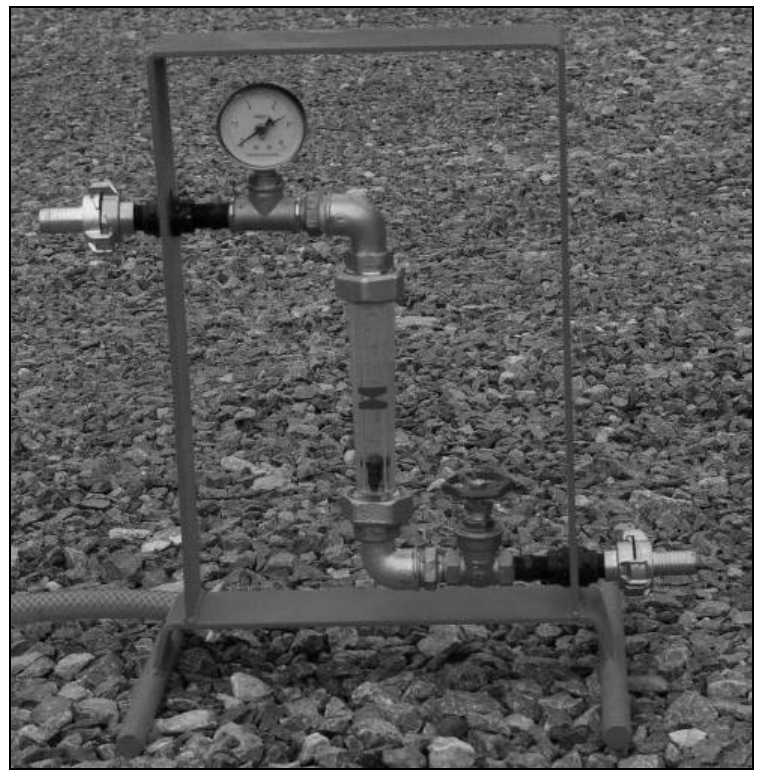

Figure 7: $\quad$ Flow indicator for water dosage.

Subsequent spraying tests were aimed at an exact specification of the resulting spray dry density. Spraying was applied to sampling rings. The dry density achieved depended mainly on the grain size of the sprayed material 


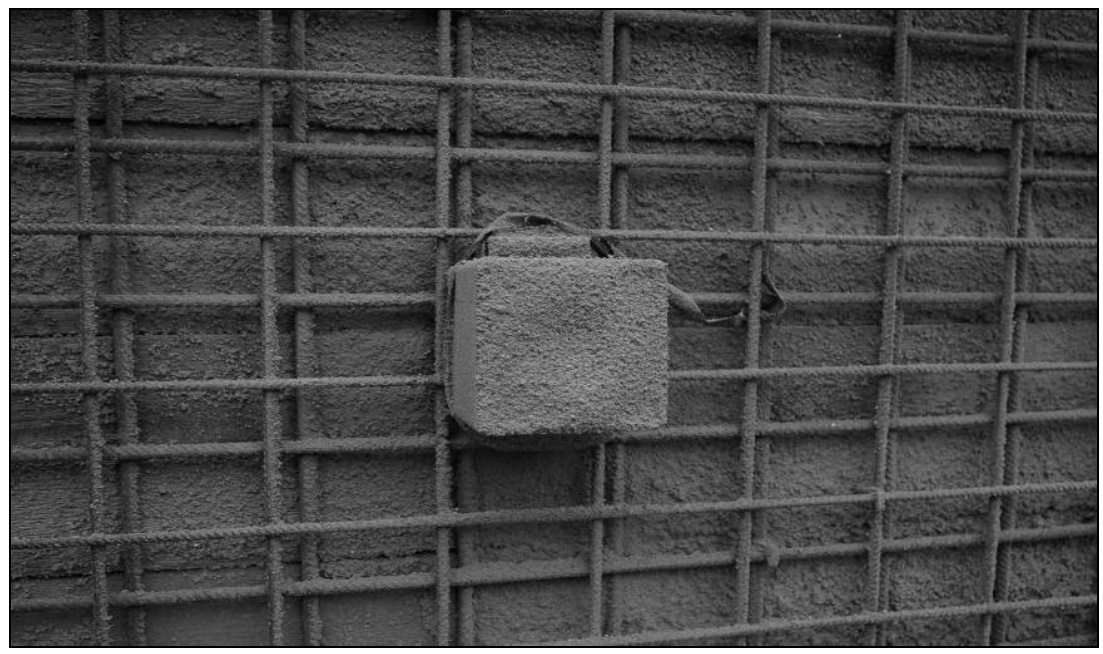

Figure 8: $\quad$ Spraying into a sampling ring.

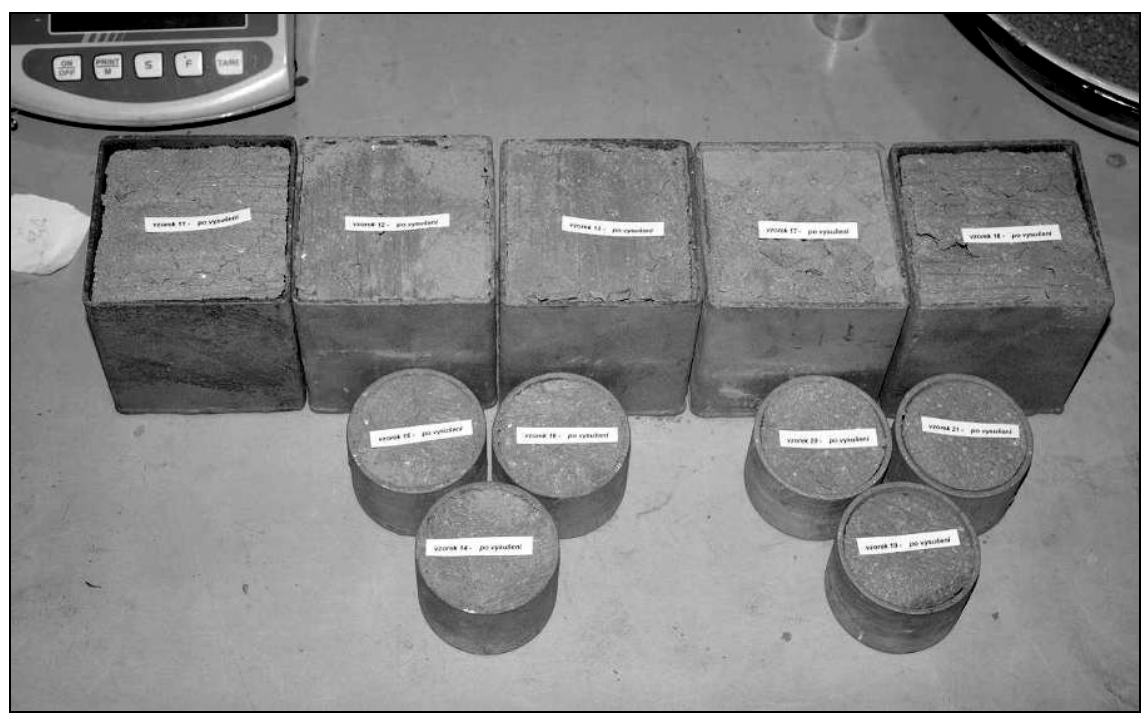

Figure 9: $\quad$ Set of sprayed samples.

applied followed by the w/c ratio selected as well as on the spraying distance between the nozzle and the spray test wall, Figures 8 and 9.

Further spraying tests are currently under preparation. 


\section{Results to date}

The development phase has led to a determination of the basic methodology of sprayed backfill, which will be further modified.

Gradual optimisation of the material and the w/c ratio produced results complying with the required dry density of $1400 \mathrm{~kg} / \mathrm{m}^{3}$ accompanied by minimum dust emissions during spraying.

A proposal for a design modification to the spraying nozzle is currently being considered and, at the same time, new, more ecological and cost-effective spraying mixtures (using fly ash) are being developed.

\section{Conclusion}

Shotclay technology is not new and has been extensively tested in connection with problems associated with radioactive waste storage in deep repositories. The application of this technology for the purposes of sprayed backfill does not set high demands on technology; it allows the use of slightly modified spraying machines commonly used in shotcreting technology.

Because of its proposed use in underground spaces, sprayed backfill technology must respect the requirement for minimum dust emissions. The spraying machine itself must be selected with a view to the ratio between its potential output and the expected size of the spaces to be backfilled.

A further prerequisite is the fine-tuning of the final composition of the sprayed mixture, i.e. bentonite or a mixture thereof with a filling agent. One of the most important requirements concerning the use of sprayed backfill technology for backfilling nuclear waste container access galleries is the attainment of dry density values no lower than those of mechanically compacted material.

In addition to its use in future deep geological repositories, it is very likely that shotclay technology, with all of the benefits it entails, will spread to other fields of the building industry.

\section{Acknowledgements}

This research could not have taken place without support from the CIDEAS (project no. 1M6840770001) and Czech Science Foundation - project no. 103/08/1691.

\section{References}

[1] Dixon, D., Concept and Technologies for Backfilling a Nuclear Fuel Waste Repository. AECL, report No: 06819-REP-01200-10103-R00, 2003.

[2] Kobayashi, I., Terada, K., \& Nonaka, K., Development of Construction Methods of the Bentonite Engineered Barrier by the High/Density Shotclay System. Proc. of the Special workshop at IDEON Science Park, Lund, Sweden, 2007. 
[3] KERAMOST, a.s., www.keramost.cz

[4] FILAMOS, s.r.o., www.filamos.cz

[5] Pacovský, J., The Use of the Mock-up-Cz Physical Model in the Design of Engineered Barriers. In: First International Conference on the Management of Natural Resources, Sustainable Development and Ecological Hazards. December 2006, Bariloche, Argentina. 